Teksty Drugie 2015, 1, s. 5-11 Special Issue - English Edition

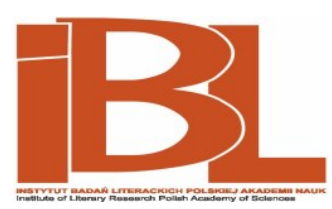

\title{
Ubi Leones
}

Grzegorz Grochowski 


\title{
Foreword
}

\author{
Grzegorz Grochowski
}

\section{Ubi Leones}

DOI: 10.18318/td.2015.en.1.1

$\mathbf{T}$ The rhetoric of the end of history may irritate today but it continues to retain its paradoxical vitality, fuelled by the influx of additional concepts. Their growth has begun with postmodernism and poststructuralism, and the list now includes also postmemory, postgender, postcolonialism, posttheater, post-politics, postsecularism, (post)traumatic postrealism, post-dependence studies (even a monograph on the anthropology of postfootball has been published recently). The fondness for such apocalyptic diagnoses was criticized once, among others, by Bruno Latour: "There is only one positive thing to be said about the postmodernists: after them, there is nothing. Far from being the last word, they mark the end of all ends"1. Ironically, Latour himself became one of the godfathers of a yet another apocalyptic movement, usually referred to as posthumanism.

There are also several terms competing with the above, circulating within the academia and referring to a similar range of phenomena: antihumanism, transhumanism, posthumanities or non-anthropocentric humanities. Each, however, sets the profile of its postulated investigation slightly differently, it

\section{Grzegorz}

Grochowski - works in the Institute of Literary Studies at the Polish Academy of Sciences, doing research in the fields of poetics, genres and discourse. He is the author of a book on text hybrids and co-author of the dictionary of Cultural Studies. He is a member of the editorial board of the journal "Teksty Drugie".

1 Bruno Latour, We Have Never Been Modern, transl. Catherine Porter (Cambridge: Harvard University Press, Cambridge, 1993), 62. 
could even be said that those individual terms include quite divergent, and sometimes contradictory, tendencies agreeing only about the notion of the exhaustion of humanistic thinking. Such multidirectionality, although troublesome to describe and discuss, should not be seen as something discouraging as similar situations are not unusual even in the traditional humanities. It will probably be best to take posthumanism as the main frame of reference, allowing us to embark on cognitive journeys into the domains delineated by the remaining terms. There are two main reasons behind my choice of such a formula. First, it does not require one to adopt a hostile attitude to the existing tradition, and thus can contain both the clearly polemical (anti-humanistic) projects as well as those that propose a rather natural law of succession. The latter is related to the second reason, namely the need to contextualize the entire question historically. And that, in turn, is because the very essence of the presumed change is frequently swept under the slogan of "objects, animals, machines" (replacing the "race, class and gender" triad of cultural studies), a gesture which decidedly detracts from the importance of the endeavor, reducing it to the level of traditional thematic criticism. Meanwhile, many signals suggest that the changes in question are more serious in nature which can only be seen from a longer temporal perspective.

Humanism is (or was, according to some) a very broad and yet a historically defined movement characterized by a certain set of views, one that influenced strongly the transformations of the entire Western culture and determined the official ideology of the humanities, especially in the area of education. As a result, it provides an important context for grasping the dynamics of the more recent intellectual trends. It is easier to leave the realm of the anecdotal and understand the current interest in the liminal forms of subjectivity if one juxtaposes the increase in the number of works about objects or animals with the symptoms of the crisis in the classical interpretation of humanity. One can see then with more clarity that a trend, which when it is analyzed in isolation may appear to be a short-term curiosity or an intellectual fad, is in fact an element of a long-term cultural process.

For posthumanism (as well as for the majority of postmodern trends) Nietzsche remains an important forerunner and inspiration, and his "Turin episode" (when the philosopher tossed his arms around a whipped horse, crying) became one of the topoi, perhaps even the founding myth, of this formation. But it was not until the 2oth century that similar movements surged. Shortly after Nietzsche, already in the 1920s, José Ortega y Gasset declared dehumanization to be the dominant feature of the entire modernity which shunned the "all too human" everyday life and "melodramatic" emotions in favor of "unheard-of gestures" and "singular figures" On the other hand, the opponents of these new trends frequently made refer-

2 José Ortega y Gasset, "The Dehumanization of Art" in Dehumanization of Art and Other Essays, transl. Helene Weyl (Princeton: Princeton University Press), 22. 
ence to humanism in a mode that grew increasingly discouraging with time, as is perfectly illustrated by the anti-modernist campaign led under the banners of the aesthetic of realism and Marxist humanism by György Lukács. His criticism of modernist literature (identified, among others, with the works of Franz Kafka) was in fact an overview of violations against the anthropocentric routine (amorphous intermixing of phenomena, excessive focus on objects, deliberate overlooking of the purposefulness of human actions), crowned with a thesis about the morbid antihumanism of the avant-garde. What followed later seems to show convincingly that the programmatic reference to humanism met with a certain degree of resistance already in the ideological debate; it was even more unfortunate in the literary reflection, as it clearly favored the normative dogma and a disregard for experimentation.

The conviction that humanism has found itself in a crisis, a sense that its rhetoric has become ossified and its solutions insufficient, were clearly verbalized as a result of war trauma. Their classic examples can be found in the ambivalent prose of Thomas Mann, even if in the popular perception the writer was often presented as a "bard of humanist values" and Lukács saw in him a defender of classical realism. While The Magic Mountain's Settembrini, as a humanist figure, is still one of the heroes of ideological psychomachia, Zeitblom, his successor from the 1948 Doctor Faustus, becomes a naive mediator of the narrative and a victim of the author's ironies. His guileless storytelling, subject to the bourgeois norms of correctness, seems to be a testimony to the cognitive helplessness of a polite philologist faced with the turbulences of dark passions, historical cataclysms and the tragedy of lonely existence. However, as far as this point is concerned, the critique of the classical model reveals also a certain hesitance and an ambiguous relation to the questioned object, as it is hard to see in Leverkühn a positive alternative to the bourgeois conventionality of Zeitblom.

It was in the same period that similar concerns were expressed in the philosophical debate. As early as in 1946 Sartre still argued that Existentialism is a Humanism, attributing positive connotations to both notions but soon afterwards Heidegger opens a new conversation in the Letter on Humanism:

the highest determinations of the essence of the human being in humanism still do not realize the proper dignity of the human being. In this respect the thinking in Being and Time is against humanism. But the opposition does not mean that such thinking aligns itself against the humane and advocates the inhumane and deprecates the dignity of the human being. Humanism is opposed because it does not set the humanitas of the human being high enough ${ }^{3}$.

3 Martin Heidegger, "Letter on 'Humanism"' in Pathmarks, ed. William McNeill, transl. Frank A. Capuzzi (Cambridge: Cambridge University Press, 1998), 251. 
And it is without doubt that Being and Time and not Being and Nothingness that remains the main point of reference for the majority of contemporary concepts (especially ones associated with posthumanism), from Giorgio Agamben's The Open to Peter Sloterdijk's Rules for the Human Zoo. While it is good to remember Adorno's sneers about Heidegger's"jargon of authenticity" in which he saw sinister glimpses of ideology, Adorno himself is hardly a defender of traditional humanism, especially since already in the Dialectic of Enlightenment he considers the separation of the subject from the world to be the original sin of the Western civilization. As a condition necessary to avoid the catastrophe, he proposes (in a spirit similar to the main currents of posthumanism) that humanity "transcend[s] its own concept of the emphatically human, positively" ${ }^{\prime \prime}$.

The pathos of old disputes may seem slightly exaggerated today but it is difficult to downplay the conviction itself, shared by such different authors, that already in their time humanism has lost the ability to explain existence and determine the order of values. The pertinence of diagnoses seem to have been confirmed indirectly by the effort made in the subsequent decades by the social sciences to dismantle structures, categories and beliefs associated with the anthropology of humanism. Colonial and gender studies, along with new historicism and cultural poetics, largely contributed to the questioning of the universalist claims of the Western model of "humanity". Critical sociology frequently showed that the skills promoted by the humanists may turn into mechanisms of distinction and perpetuate social injustice (despite a declarative recognition of egalitarian ideals). Postructuralism, allied with psychoanalysis, brought a criticism of rationality, uniformity and self-transparency of the subject, significantly weakening the cognitive optimism of the humanities. A culmination of those critiques may be found in the Foucauldian "death of the subject", directed against taking the figure of an abstract, universal subject as the main principle of our thinking.

Although the crisis of the classical vision of man is an important context for the discussed changes, it would be unjust to view their field in terms of rubble remaining after the demolition of humanism. Indeed, as a separate formation, posthumanism attempts to create new strategies and descriptive categories allowing it to reach "where lions live" (ubi leones), in other words, the non-representable areas of the non-human. What seems notable about such pursuits is their performative reformulation of the issue of subjectivity (that heretofore used to occupy the center of the humanities) or even need to replace it with a reflection on "agency" which does not impose binding references to intention, awareness, function, sense or purpose. This shift in emphasis results in a broad definition of potential "agents" and paves the way for the reflection on the actions of marginalized minorities, handicapped sub-

4 Theodor Adorno, "Messages in a Bottle" in Mapping Ideology, ed. Slavoj Žižek (London and New York: Verso, 2012), 37. 
jects, or even "non-human actors" - animals, artifacts, material traces, anonymous mechanisms. Sometimes, in fact, it questions the very possibility of distinguishing the human being from the abundance of other phenomena.

Numerous similar formulations are related directly to the postulates and values associated with environmentalism and it is sometimes difficult to avoid an impression that, despite postulated reservations, some of them slip into a naive Rousseauism, sprinkled with political moralizing and spiritual New Ageist monism (facilitated by the proclamatory mode of the contemporary practice within the humanities). Rarely does one hear concern about the strangeness of that which may be encountered during the expeditions into the areas of non-human existence. For the sake of counterbalance, then, it may be worth to recall one of Werner Herzog's works: in the famous Grizzly Man the director attempts to present the story of Timothy Treadwell who took the notion of a lack of boundaries between the animal and human worlds very literally and consequently his romantic adventure with nature ended with him being torn apart by bears. Herzog provides an authorial commentary for this sequence of tragic events, revealing not so much natural harmony but rather the merciless cruelty of nature: "what haunts me is that in all the faces of all the bears that Treadwell ever filmed, I discover no friendship, no understanding, no mercy. I see only the overwhelming indifference of nature. To me, there is no such thing as a secret world of the bears. And this blank stare speaks only of a half-bored interest in food".

I do not mean to use a drastic exemplum to undermine the validity of the discussed approaches, instead, I am trying to point out the fundamental ambiguity, the eternal problematics of the relationships between species. It seems that a radical discourse of renouncement (i.e. one that ignores the diversity of positions and suggests an already defined outcome as if the overcoming of traditional thinking was a fait accompli and not a proposal) tends to lean toward naive answers and is often susceptible to expedient appropriations. It reminds me of the recent excessively enthusiastic respect for the Other which through a one-sided celebration of radical difference reduced it to the role of a conceptual fetish or ethical bogyman. Similarly, a complete openness and simplistic affirmation of the non-human carries the risk of its inaccessibility being replaced by sentimental clichés.

Most of the works included in this volume present a different approach, closer to the cautiously critical position. Its specificity can be summarized in three points. First, the collected texts avoid the easy demonization of traditional orders and locate the presumed or postulated turn toward posthumanism within a dynamic of historical and civilizational transformations which change the sensibilities of the participants of culture. Second, the authors in general do not deny the existence of generic divisions nor try to nullify them with some radical gestures but rather problematize their attributed status, for instance through a historical analysis of the creation of differences. Finally, crossing the borders of anthropocentrism is viewed

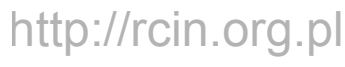


with approval but without excessive optimism, in other words, as a normative postulate (perhaps an inevitably utopian one) or a risky challenge, tempting with the potential to reshape the existing forms of representation.

What seems particularly interesting is the question of how the attempts to touch the non-human translate to specific textual solutions, especially in the creative arts. So far the matter remains poorly diagnosed but it appears noteworthy insofar as one could imagine here a considerable diversity of auctorial poetics and strategies. Since discussions of this kind can be found in the following volume, I will mention briefly only one example, removed slightly from the mainstream of current research, namely the somewhat forgotten Alain Robbe-Grillet, a representative of the French nouveau roman who in the late 1950 s criticized the traditional narrative (mainly in his programmatic"Nature, Humanism and Tragedy"). Robbe-Grillet attacked mainly the anthropomorphic metaphors dominant in the literary imagination which tell us, he says, to treat nature as a kind of counterpart of human experience leading to an inevitable rupture in the face of the silence of objects. To Robbe-Grillet, looking for sense in the non-human world, cultivated within the humanities, remains a superstition rooted in the mythology of "deeper meaning" and leading to the misery, or the tragic alienation of human existence. If literature is to liberate man, it should denounce the "lie of humanism" and follow science in its utilitarian approach to nature, giving up on the fantasy of a kinship of beings. A possible cure for metaphysical anxieties could be found via representations of the non-human world performed without an anthropocentric mediation, which in Robbe-Grillet's program leads to the postulate of formalization, or even geometrization, of description. Dispassionate measurements of proportions, determining distances, cataloging shapes, comparing cones and polyhedra were to allow for a representation of the world of objects which, freed of the burden of symbolic meanings, could then refer only to themselves.

Later reception was generally rather skeptical about the success of this project and it would be difficult to find authors arguing that narrative experiments managed to liberate man from the tragedy of existence and the existential rupture. It is also doubtful whether the scientific approach indeed should be viewed as free of anthropocentric limitations. Today in particular, with the rising wave of suspicion against the scientific ideology, scientific discourse is frequently seen as a cultural construct used to perpetuate human dominion over the world. Also the poetics of RobbeGrillet's own novels move away from his program enkindling further doubts about the potential effectiveness of his proposals. Critics often point to their involuntary metaphorical potential and see in the supposedly neutral and dry reconstructions images of human alienation, loneliness and objectification.

Further doubts can be addressed but they have little impact on the assessment of the writer himself - indeed, unrealistic expectations tend to accompany the majority of artistic endeavors and there is nothing exceptional about the discrepancies between the artist's postulated program and practice, especially in the case of 
avant-garde artists. But the internal tensions and contradictions of Robbe-Grillet's project, his struggle with the conventions and tradition as well as the intricacy of his argument exemplify the problematics of the attempts to venture beyond the anthropocentric perspective. One can clearly see that criticism of the symbolic order often results in its reshaping while an austere description that at some point in time becomes a phenomenology of actuality and a touch of the thing itself, a moment later may reveal itself as an intertextual shift and another convention. This does not detract in the least from the purposefulness of the explorations that distort customary formulas but is rather to remind that the question of our relation to the non-human remains unanswered.

Translation: Anna Warso 